\title{
Clinical research of individualized therapy in advanced esophageal cancer based on the ERCC1 C8092A genotype
}

\author{
YI-WEI YAO, YI-FU HE, XING-HUA HAN, CHU-SHU JI and BING HU \\ Department of Medical Oncology, Anhui Provincial Hospital Affiliated to Anhui Medical University, \\ Hefei, Anhui 230001, P.R. China
}

Received June 29, 2016; Accepted April 10, 2018

DOI: $10.3892 / \mathrm{ol} .2018 .8894$

\begin{abstract}
The present study aimed to explore the role and clinical value of the detection of Excision repair cross-complementing 1(ERCC1) C8092A polymorphisms in individualized therapy of patients with advanced esophageal cancer. A total of 127 patients with advanced esophageal cancer were enrolled between January 2010 and January 2014 in Anhui Provincial Hospital. Patients were randomly assigned in a 1:2 ratio to a standard treatment group or an individualized treatment group, respectively, prior to ERCC1 C8092A assessment. Patients in the standard treatment group were treated with paclitaxel and cisplatin. The DNA was obtained from the peripheral blood of individualized treatment patients, amplified by PCR and sequenced to determine the ERCC1 C8092A polymorphism prior to the administration of chemotherapies. Patients with the ERCC1 C8092A genotype of $\mathrm{A} / \mathrm{A}$ or $\mathrm{A} / \mathrm{C}$ received paclitaxel and cisplatin, and those with the genotype of $\mathrm{C} / \mathrm{C}$ received paclitaxel and fluorouracil. The primary endpoint was response rate (RR). The secondary endpoints included toxicity of chemotherapy, progression-free survival (PFS) and overall survival (OS) times. Differences between the groups were evaluated by $\chi^{2}$ test. Differences in survival were analyzed by Kaplan-Meier survival curves. The survival rate was analyzed by log-rank test. Follow-up data was obtained until December 2015. The RR was obtained for 15 patients $(34.8 \%)$ in the standard treatment group and 45 patients $(53.6 \%)$ in the individualized treatment group $\left(\chi^{2}=3.095\right.$; $\mathrm{P}=0.046)$. For adverse events, nausea and vomiting and anemia were significantly decreased in the individualized treatment group compared with the standard treatment group $(\mathrm{P}=0.001$ and $\mathrm{P}=0.004$, respectively). The median progression free survival time was 4.4 months [ $95 \%$ confidence
\end{abstract}

Correspondence to: Professor Bing Hu, Department of Medical Oncology, Anhui Provincial Hospital Affiliated to Anhui Medical University, 17 Lujiang Road, Hefei, Anhui 230001, P.R. China E-mail: hubing3756@hotmail.com

Key words: esophageal cancer, individualized therapy, cisplatin, excision repair cross-complementing 1 interval (CI)3.8-5.0 months] in the standard treatment group and 6.6 months (95\% CI, 5.8-7.4 months) in the individualized treatment group $(\mathrm{P}=0.018)$. The median overall survival time was 11.4 months (95\% CI, 10.1-12.7 months) in the standard treatment group and 14.2 months (95\% CI, 13.2-15.2 months) in the individualized treatment group $(\mathrm{P}=0.008)$. The RR, toxicity of chemotherapy, PFS and OS were significantly improved in the individualized treatment group compared with the standard treatment group. Detection of ERCC1 gene polymorphisms maybe performed for patients with advanced esophageal cancer to improve individualized therapy, which requires additional study.

\section{Introduction}

Esophageal cancer is a type of malignant tumor originating from the esophageal mucus epithelia or glands. It is also one of the most commonly-identified malignant GI tract tumor types in China (1). There are two main factors that cause esophageal cancer. The first is lifestyle factors including high-temperature beverages, heavy alcohol drinking and tobacco smoking. The second is genetic predisposition in a population (2). The incidence rate of esophageal squamous cell carcinoma (ESCC) in China is significantly increased compared with that in the USA (3). As the disease presentation of early-stage ESCC varies extensively, the majority of patients exhibit mid-to advanced-stage disease when clinically diagnosed. The majority of patients are treated predominantly by a combination of chemo- and radiotherapy instead of surgery (4). Chemotherapeutic drugs that are recommended by the National Comprehensive Cancer Network in the United States of America include cisplatin, paclitaxel, irinotecan, docetaxel, fluorouracil and epirubicin (5). Cisplatin is the primary choice among these for advanced esophageal cancer in China, due to its high single-drug efficiency and relatively cheap price (6). However, the single-drug efficiency of cisplatin in esophageal cancer treatment remains $20 \%$, and the efficiency of cisplatin-based chemotherapy is not $>50 \%$ (7). These data indicates that a certain group of patients may not benefit from the chemotherapy using cisplatin, but also suffer from the adverse effects of the treatment and the associated financial burden (8).

Individuals react differently to the same drug, which is hypothesized to result from distinctions with in individual 
genomes. Gene polymorphisms are the primary factor that causes this variance between individuals (9). The C8092A polymorphism of the Excision repair cross-complementation group 1 (ERCC1) gene have three genotypes, wild-type ERCC1-8092 (C/C genotype), the heterozygous mutation of ERCC1-8092 (C/A genotype) and the homozygous mutation of ERCC1-8092 (A/A genotype). It has been demonstrated that the C8092A polymorphism of the ERCC1 gene is significantly associated with the outcome of platinum treatment in nasopharyngeal and lung cancer, pleural mesothelioma, breast cancer and ovarian cancer (10-14). Bradbury et al (15) investigated 150 patients with esophageal cancer treated with chemoradiation therapy using platinum, and identified that the patients possessing an ERCC1-8092 A/A genotype or A/C genotype exhibited improved disease-free survival and overall survival (OS) compared with the patients with the $\mathrm{C} / \mathrm{C}$ genotype $(\mathrm{P}=0.04$ and $\mathrm{P}=0.03$, respectively). Our previous study also indicated that among patients with advanced esophageal cancer treated by cisplatin and fluorouracil, the $\mathrm{A} / \mathrm{A}$ or $\mathrm{A} / \mathrm{C}$ patient groups demonstrated improved response rates (RR) and progression-free survival (PFS) compared with the $\mathrm{C} / \mathrm{C}$ group (8). These results indicate that $\mathrm{A} / \mathrm{A}$ and $\mathrm{A} / \mathrm{C}$ patients are likely to be more sensitive to platinum compared with patients with the $\mathrm{C} / \mathrm{C}$ polymorphism (16). However, whether differentiation of treatments for esophageal cancer based on the ERCC1 C8092A genotype may increase the efficiency of chemotherapy and prolong the survival of patients in China remains unknown. Therefore, in order to verify this hypothesis, and to optimize the individualized treatment for patients with advanced esophageal cancer. These patients of the individualized treatment group were treated based on their ERCC1 C8092A genotype. The outcomes, including RR, PFS, OS and adverse events, from the standard and individualized treatment groups were analyzed.

\section{Materials and methods}

Patients. Anhui Provincial Hospital Oncology Department (Hefei, China), Anhui Provincial Cancer Hospital Oncology Department (Hefei, China) and Anhui Provincial Cardiovascular Hospital Oncology Department (Hefei, China) all maintain prospective databases. Eligible patients exhibited histologically confirmed advanced squamous cell carcinoma of esophagus and measurable lesion(s). All patients provided written informed consent. The present study was approved by the Clinical Research Ethics Committee of the Anhui Provincial Hospital. Other inclusion criteria were: Histologically confirmed un-resectable or recurrent advanced esophageal cancer following surgery; Eastern Cooperative Oncology Group performance status (ECOG-PS) $\leq 2$, survival not $<3$ months; clinically measurable lesion(s); last dose of adjuvant chemotherapy occurred no later than 6 months ago or no history of chemotherapy; and adequate hematological, hepatic and renal functions for chemotherapy. Patients were excluded if they had psychiatric disease, severe cardiological, pulmonary, hepatic or renal diseases, suffered from colitis gravis or were pregnant. A total of 140 patients were enrolled in the present study. Patients were followed up primarily by clinic visits, phone calls and e-mails until December 2015. Follow-up information included measurement of lesions, tumor markers (carcinoembryonic antigen and SCC) and ECOG-PS. Among the patients, genotyping information was not available for 3 patients, 4 failed to receive the protocol treatment due to adverse events, 2 were determined to be non-evaluable and an additional 4 were lost to follow-up. Therefore, 127 patients were analyzed. Of those, 49 were female $(38.6 \%)$ and 78 were male $(61.4 \%)$; 21 were aged $<60$ years $(16.5 \%)$ and 106 were aged $\geq 60$ years $(83.5 \%)$. The clinical stages of esophageal cancer were classified in accordance with the internationally accepted tumor node-metastasis (TNM) staging system (7th edition) (17,18). A total of 75 exhibited low differentiation (59.1\%), 37 exhibited mid differentiation (29.1\%) and 15 exhibited high differentiation (11.8\%).

Treatment. The standard regimen consisted of cisplatin $\left(25 \mathrm{mg} / \mathrm{m}^{2}\right.$ from days 1 to 3$)$ and paclitaxel $\left(150 \mathrm{mg} / \mathrm{m}^{2}\right.$ on day 1). The length of standard regimen was 3 days. For the individualized treatment group, blood samples were obtained for the ERCC1-C8092A genotype analysis prior to initiation of treatment. If the genotype was not $\mathrm{C} / \mathrm{C}$, the regimen was the same as the standard regimen, otherwise the regimen consisted of fluorouracil $\left(750 \mathrm{mg} / \mathrm{m}^{2}\right.$ from days 1 to 5$)$ and paclitaxel $\left(150 \mathrm{mg} / \mathrm{m}^{2}\right.$ on day 1$)$ which took 5 days to complete. These regimens were repeated every 21 days as one cycle. Patients continued to be treated with the regimen according to the protocol until progressive disease (PD) was confirmed according to a contrast computed tomography or magnetic resonance imaging scan. If PD was confirmed, the regimen was either changed to second-line chemotherapy or supportive treatment according to the ECOG-PS of the patients. All patients completed $>2$ cycles of chemotherapy. The maximum number of chemotherapy cycles was 6 cycles.

Response evaluation. Response Evaluation Criteria in Solid Tumors version 1.1 (19) was used for efficacy assessment. Complete response (CR) was defined as the disappearance of all lesions and no recurrence over a 4 -week period. Partial response (PR) was defined as $\geq 30 \%$ decrease in the tumor sum of longest diameters (SLD) and PD as $\geq 20 \%$ increase in the SLD or the occurrence of new lesions. Stable disease (SD) was calculated as non-PR/PD, and response rate (RR) was calculated using the following formula: $R R=C R+P R$. PFS was defined as the time interval between inclusion and the first progression or mortality from all causes. OS was defined as the time interval between inclusion and mortality from all causes. The response evaluation was performed every 2 weeks. If symptoms that supported PD were observed in the clinic, the evaluation was performed prior to the date predetermined within the protocol. If PD was confirmed, the regimen was either changed or optimized to better support the treatment. Patients with CR, PR or SD continued to be treated with the regimen on protocol for a maximum of 6 cycles, until PD was confirmed. Lesions in all the patients that discontinued chemotherapy were evaluated every month.

Adverse events and adjustments. The toxicity of the chemotherapy was graded according to National Cancer Institute Common Terminology Criteria for Adverse Events version 4.03 (20). Treatment for adverse events was 

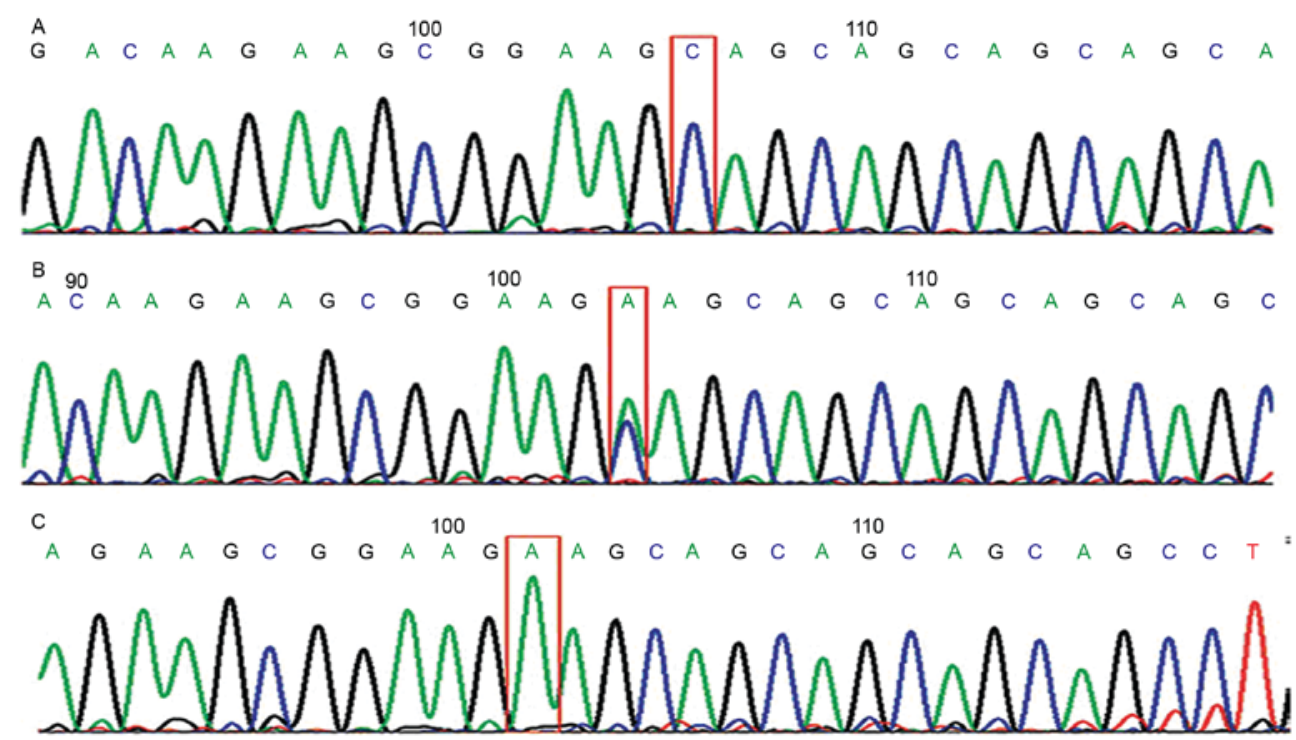

Figure 1. Representative sequencing results of the ERCC1 C8092A gene from patients in. The (A) ERCC1 C8092A C/C group, (B) ERCC1 C8092A A/C group and (C) ERCC1 C8092A A/A group. Red boxes show the point mutation of the sequence of DNA. ERCC1, Excision repair cross-complementation group 1.

administered to all grade 1 and 2 toxicities, and the original regimen was continued when adverse events were alleviated. Regimen dose was decreased by $25 \%$ for all grade 3 and 4 toxicities and discontinued in case of recurrence and persistence. To increase patient tolerance of chemotherapy, adjuvant treatment using anti-emetics, hydration and diuretics drugs was also administered over the period of chemotherapy. Granulocyte colony-stimulating factor was administered to grade 3 and grade 4 myelotoxicities 24 h after chemotherapy.

Genotype analysis of ERCC1 C8092A. Promoter and coding single nucleotide polymorphisms (SNPs) in ERCC1 C8092A (rs3212986) in the SNP database of the National Center for Biotechnology Information (BUILD 151; http://www. ncbi.nlm.nih.gov/SNP) were sourced. The DNA of eukaryotes in peripheral blood of patients was obtained using phenol-chloroform extraction and analyzed with polymerase chain reaction (PCR) amplification. The primers for PCR was prepared by Sangon Biotech Co., Ltd. (Shanghai, China). The PCR primers used to amplify the DNA were as follows: ERCC1-8092 Forward, 5'-ACAGTGCCCCAAGAGGAGAT-3' and reverse, 5'-AGTCTCTGGGGAGGGATTCT-3'. The reaction mixture consisted of: 10X buffer solution (Sangon Biotech Co., Ltd.) (15 mmol/1 $\left.\mathrm{Mg}^{2+}\right), 2 \mu 12.5 \mathrm{mM}$ dNTPs $(2.5 \mathrm{mmol} / \mathrm{l})$, $0.5 \mu \mathrm{l}$ of each primer $(10 \mathrm{mmol} / \mathrm{l}), 0.2 \mu \mathrm{l}$ Taq (Sangon Biotech Co., Ltd.) enzyme (5 U/ $\mu \mathrm{l}), 50 \mathrm{ng}$ genomic DNA sample and sterile distilled water (total volume, $50 \mu \mathrm{l}$ ). The thermo cycler conditions were as follows: $95^{\circ} \mathrm{C}$ for $5 \mathrm{~min}$; then, $94^{\circ} \mathrm{C}$ for $15 \mathrm{sec}, 60^{\circ} \mathrm{C}$ for $25 \mathrm{sec}$ and $72^{\circ} \mathrm{C}$ for $30 \mathrm{sec}$ for 40 cycles, then $72^{\circ} \mathrm{C}$ for $10 \mathrm{~min}$. The products were kept at $4^{\circ} \mathrm{C}$ until use. The products of PCR were sequenced by Sangon Biotech Co., Ltd., and the gene polymorphisms were analyzed. The genotypes were identified using MxPro-Mx3000P v4.00 analysis software (Agilent Technologies, Inc., Santa Clara, CA, USA). The data were analyzed using the $2^{-\Delta \Delta C q}$ method (21). The sequence chromatograms were analyzed using Chromas software v2.0 (Technelysium Pty Ltd., South Brisbane, Australia) to search for SNPs at the target locus of each gene.
Statistical analysis. Statistical analyses were performed using SPSS software version 17.0 (SPSS, Inc., Chicago, IL, USA). Prior to analysis, the Hardy-Weinberg equation for the equilibrium of allele distributions was used to statistically evaluate the data along with the $\chi^{2}$ test. The quantitative data was presented as frequencies and percentages while quantitative data with a normal distribution was presented as the mean \pm standard deviation.

The distribution of demographic variables was compared between groups through nonparametric tests. The Mann-Whitney U test was used to compare the data between two groups. The Kruskal-Wallis test was used to compare the data between three groups. The response rate was evaluated along with the $\chi^{2}$ test or Fisher's exact test for $2 \times 2$ contingency tables.

Independent influential factors of treatment were assessed using logistic regression analysis, with variables significant in the univariate analysis were included into a multivariate model. All testing was 2-sided with significance determined at $\mathrm{P} \leq 0.05$.

All survival analyses were performed with the Kaplan-Meier method. Survival rate was evaluated by the log-rank test. The significance level $\alpha$ was 0.05 , and $\mathrm{P}<0.05$ was considered to indicate a statistically significant difference.

\section{Results}

Sequencing of ERCC1 C8092A genes and genetic equilibrium test. The sequencing result of the ERCC1 C8092A genes from 84 individualized treated patients is presented in Fig. 1. According to the Hardy-Weinberg Principle, the Hardy-Weinberg equilibrium was reached in the distribution of genotypes, indicating that the samples were from the same Mendelian population ( $\mathrm{P}>0.05$; Table I).

Clinical characteristics in treatment groups. The sex, median age, ECOG-PS, TNM staging and pathological differentiation grading were not significantly different between the 
Table I. Genetic equilibrium test in the individualized treatment group.

\begin{tabular}{lccc}
\hline Genotype & $\mathrm{N}$ & $\chi^{2}$ & P-value \\
\hline ERCC1 C8092A & 84 & 0.7001 & $0.402^{\mathrm{a}}$ \\
$\mathrm{A} / \mathrm{A}$ & 14 & & - \\
$\mathrm{A} / \mathrm{C}$ & 36 & & - \\
$\mathrm{C} / \mathrm{C}$ & 34 & & - \\
\hline
\end{tabular}

${ }^{\mathrm{a}}$ Hardy-Weinberg equation for the equilibrium of allele distributions along with the $\chi^{2}$ test. ERCC1, Excision repair cross-complementation group 1 .

individualized and the standard treatment groups based on the $\chi^{2}$ or Mann-Whitney U test results (Table II).

$R R$. The RR of the individualized and standard treatment groups were 53.6 and $34.8 \%$, respectively, which were significantly different $(\mathrm{P}=0.046)$. Within the individualized treatment group, the RR of the patients with non-C/C genotypes was $52.0 \%$, and the RR of the patients with the $\mathrm{C} / \mathrm{C}$ genotype was $55.8 \%$, which were not significantly different $(\mathrm{P}=0.726$; Table III). Multivariate analysis indicated that the ECOG-PS, individualized treatment, high differentiation of tumors and the TNM staging were all independent prognostic factors of RR (Table IV).

Adverse events. The adverse events in the two groups were primarily nausea and vomiting, hair loss, myelotoxicity and neurotoxicity. In the individualized treatment group, the rate of nausea and vomiting was $89.3 \%$ (75/84), within which the rate of grade 3-4 events was $33.3 \%$ (28/84). In the standard treatment group, the rate of nausea and vomiting was $97.7 \%$ (42/43), within which the rate of grade 3-4 events was $65.1 \%$ (28/43). The rates of nausea and vomiting in general from the two groups were significantly different $(\mathrm{P}=0.001)$. In the individualized treatment group, the rate of anemia was $91.6 \%$ (77/84), within which the rate of grade 3 to 4 events was $17.9 \%$ $(15 / 84)$. In the standard treatment group, the rate of anemia was $95.3 \%$ (41/43), within which the rate of grade 3 to 4 events was $32.5 \%(14 / 43)$. These rates of anemia in general from the two groups were significantly different $(\mathrm{P}=0.004)$. In the individualized treatment group, the rates of hair loss, aleukocytosis and neurotoxicity were 100.0 (84/84), 94.0 (79/84), and $84.5 \%$ (71/84), respectively. In the standard treatment group, the rates of hair loss, aleukocytosis and neurotoxicity were $100.0(43 / 43), 90.7$ (39/43), and 83.7\% (36/43), respectively. The rates from the two groups were not significantly different from each other $(\mathrm{P}>0.05)$. Other adverse events such as diarrhea, thrombocytopenia, hepatic and renal toxicity were less common, and the rates from the two groups were not statistically different (Table V).

PFS and OS. The PFS in the standard treatment group was 4.4 months [95\% confidence interval (CI), 3.8-5.0 months], and the PFS in the individualized treatment group was 6.6 months (95\% CI, 5.8-7.4 months), which were significantly different $(\mathrm{P}=0.018)$. The $\mathrm{OS}$ in the standard treatment group was 11.4 months (95\% CI, 10.1-12.7 months), and the OS in the individualized treatment group was 14.2 months (95\% CI, 13.2-15.2 months), which were significantly different $(\mathrm{P}=0.008)$. In the individualized treatment group, the $\mathrm{PFS}$ in the $\mathrm{A} / \mathrm{C}$ or $\mathrm{A} / \mathrm{A}$ groups was 6.5 months $(95 \% \mathrm{CI}$, 5.4-7.6 months), and the PFS in the C/C group was 6.6 months (95\% CI, 5.3-7.9 months), which were not significantly different $(\mathrm{P}=0.139)$. The $\mathrm{OS}$ in $\mathrm{A} / \mathrm{C}$ or $\mathrm{A} / \mathrm{A}$ groups was 14.2 months (95\% CI, 13.2-15.2 months), and the OS in $\mathrm{C} / \mathrm{C}$ group was 13.5 months (95\% CI, 11.6-15.4 months), which were not significantly different ( $\mathrm{P}=0.512$; Table VI; Figs. 2 and 3).

\section{Discussion}

Cisplatin is one of the primary compounds used in the chemotherapy of esophageal cancer, due to its efficacy and relatively low price (22). By forming a platinum-DNA complex in the tumor cell, intra- or inter-strand cross links are formed, resulting in the termination of cell cycle at $\mathrm{G} 2 / \mathrm{M}$ phase, which consequently triggers apoptosis in the proliferating cells (23). However, DNA repairing mechanisms are responsible for the integrity and stability of the genetic information. On one hand, when exogenous factors cause changes in the DNA, the cell repairs the DNA through these mechanisms to prevent additional damage to the cell. Conversely, when the DNA of tumor cells are damaged in chemotherapy, the same repairing system is also able to fix the damaged DNA and ensure that the tumor cells survive the chemotherapy. Therefore, it is hypothesized that the sensitivity and resistance to chemotherapy of tumors are associated with DNA repairing mechanisms. In the human body, there are 6DNA repair processes: Base excision repair, mismatch repair, homologous recombination (HR), non-homologous end joining, trans lesion DNA synthesis and nucleotide excision repair (NER) (24). Among those, NER is primarily responsible for repairing the DNA adducts induced by polycyclic aromatic hydrocarbons, ultraviolet light and other exogenous chemicals $(25,26)$. With respect to platinum-induced DNA damage in chemotherapy, NER is a multi-functional repairing system. By excising the DNA adduct and replicating DNA from the complementary strand, NER retains the integrity of the genome (27).

ERCC1 is located on the chromosome 19q13.2-13.3. The whole gene consists of $15 \mathrm{kbp}$ and encodes a protein of 297 amino acid residues (28). ERCC1 has to form a heterodimer with DNA repair endonuclease XPF (XPF), which is responsible for the recognition and incision of the damaged DNA strand 5' of the lesion. This step is the rate-determining step in NER, and also an important step for the regulation of NER (29-31). The activity of ERCC1 indicates the activity of the repair system of NER (32). The over expression of ERCC1 increased the clearance level of platinum-DNA adducts induced by cisplatin and leads to the resistance of cisplatin in patients. Previous studies have demonstrated that the ERCC1-C8092A polymorphism is relevant to the outcome of platinum treatment, and that the patients with $\mathrm{A} / \mathrm{A}$ and $\mathrm{A} / \mathrm{C}$ genotypes are likely to be more sensitive to platinum treatment compared with the patients with the $\mathrm{C} / \mathrm{C}$ genotype $(11,33)$. Bradbury et al $(15)$ investigated 150 patients with esophageal cancer treated with platinum-based chemo radiation therapy, and identified that the patients possessing an 


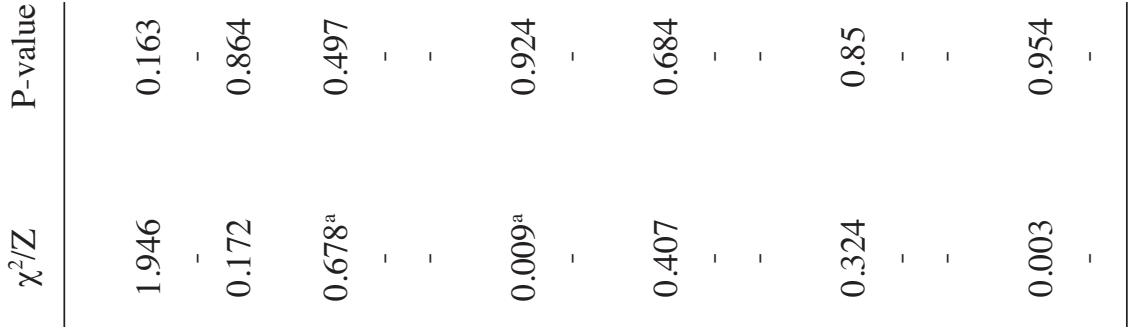

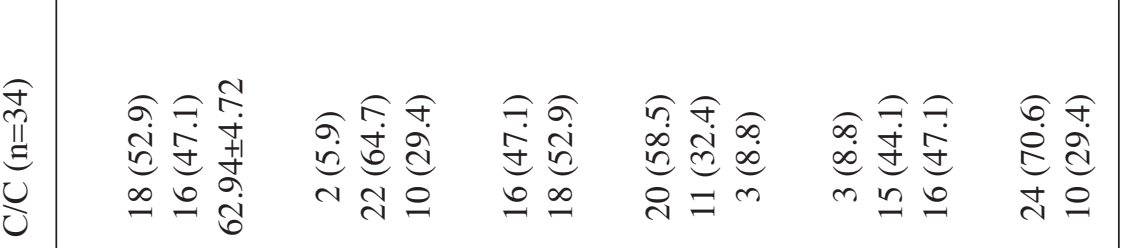

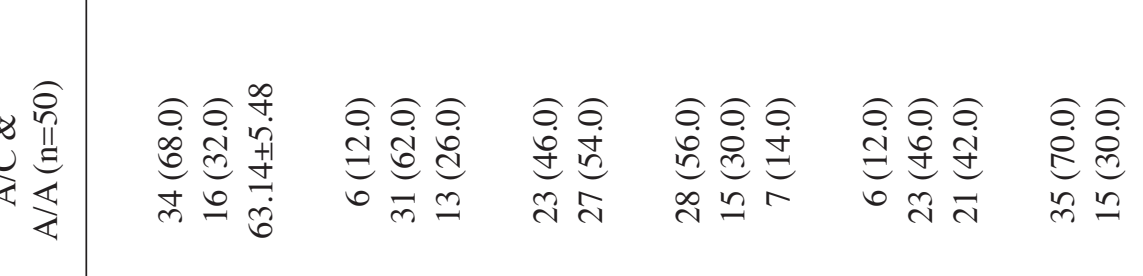

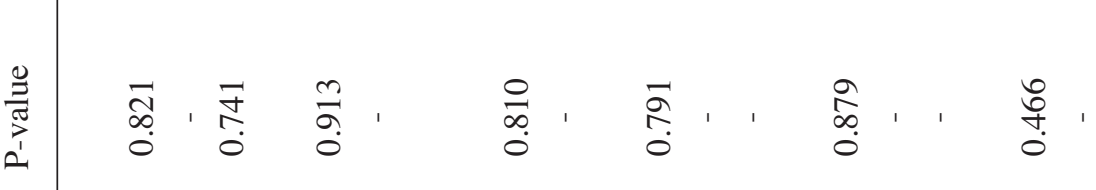

N

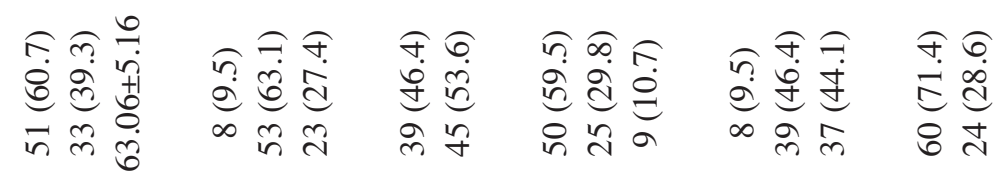

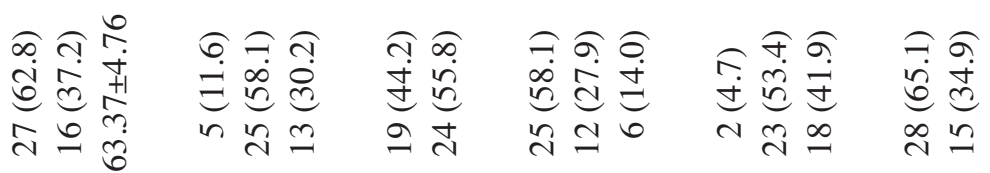


Table III. Comparison of RR.

\begin{tabular}{|c|c|c|c|c|c|}
\hline Patient grouping & Response $(\mathrm{CR}+\mathrm{PR}), \mathrm{n}$ & No response $(\mathrm{SD}+\mathrm{PD}), \mathrm{n}$ & $\mathrm{RR}(\%)$ & $\chi^{2}$ & P-value \\
\hline Standard treatment group & 15 & 28 & 34.8 & 3.095 & 0.046 \\
\hline Individualized treatment group & 45 & 39 & 53.6 & & \\
\hline $\mathrm{A} / \mathrm{C}$ and $\mathrm{A} / \mathrm{A}$ & 26 & 24 & 52.0 & 0.123 & 0.726 \\
\hline $\mathrm{C} / \mathrm{C}$ & 19 & 15 & 55.8 & & \\
\hline
\end{tabular}

RR, Response Rate; CR, complete response; PR, partial response; SD, stable disease; PD, progressive disease.

Table IV. Univariate and multivariate analyses.

\begin{tabular}{|c|c|c|c|c|}
\hline \multirow[b]{2}{*}{ Variables } & \multicolumn{2}{|c|}{ Univariate analysis } & \multicolumn{2}{|c|}{ Multivariate analysis } \\
\hline & OR $(95 \% \mathrm{CI})$ & P-value & OR $(95 \% \mathrm{CI})$ & P-value \\
\hline \multicolumn{5}{|l|}{ Sex } \\
\hline Male & 1 & - & - & - \\
\hline Female & $1.044(0.509-2.142)$ & 0.906 & - & - \\
\hline \multicolumn{5}{|l|}{ Age, years } \\
\hline$\geq 60$ & $1.236(0.481-3.179)$ & 0.660 & - & - \\
\hline$<60$ & 1 & - & - & - \\
\hline \multicolumn{5}{|l|}{ ECOG-PS } \\
\hline 0 & 1 & - & 1 & - \\
\hline 1 & $0.369(0.094-1.443)$ & 0.152 & $0.486(0.114-2.078)$ & 0.331 \\
\hline 2 & $0.072(0.016,0.335)$ & 0.001 & $0.146(0.028-0.771)$ & 0.023 \\
\hline \multicolumn{5}{|l|}{ Treatment } \\
\hline Standard & $0.464(0.217-0.992)$ & 0.048 & $0.377(0.152-0.931)$ & 0.034 \\
\hline Individualized & 1 & - & 1 & - \\
\hline \multicolumn{5}{|l|}{ Treatment } \\
\hline Standard & $1.169(0.482-2.806)$ & 0.726 & - & - \\
\hline $\mathrm{C} / \mathrm{C}$ & $0.495(0.214-1.142)$ & 0.099 & - & - \\
\hline $\mathrm{A} / \mathrm{C} \& \mathrm{~A} / \mathrm{A}$ & 1 & - & - & - \\
\hline \multicolumn{5}{|l|}{ Status-OS } \\
\hline 0 & 1 & - & - & - \\
\hline 1 & $0.894(0.055-14.612)$ & 0.937 & - & - \\
\hline \multicolumn{5}{|l|}{ Histologic grade ${ }^{a}$} \\
\hline G3 & 1 & - & 1 & - \\
\hline G2 & $2.750(1.224-6.177)$ & 0.014 & $1.617(0.629-4.155)$ & 0.318 \\
\hline G1 & $9.333(2.444-35.636)$ & 0.001 & $6.858(1.583-29.711)$ & 0.010 \\
\hline \multicolumn{5}{|c|}{ Location of tumor } \\
\hline Cervical & 1 & - & - & - \\
\hline Middle & $1.586(0.421-5.980)$ & 0.496 & - & - \\
\hline Lower & $1.687(0.443-6.428)$ & 0.443 & - & - \\
\hline \multicolumn{5}{|l|}{ TNM staging } \\
\hline 3 & 1 & - & 1 & - \\
\hline 4 & $0.213(0.101-0.452)$ & $<0.001$ & $0.355(0.144-0.874)$ & 0.024 \\
\hline
\end{tabular}

ERCC1 C8092A genotype of A/A or A/C exhibited improved PFS and OS compared with the patients with the C/C genotype
( $\mathrm{P}=0.03$ and $\mathrm{P}=0.04$, respectively). Wang et al (33) also demonstrated that in a trial with 256 patients with esophageal cancer 
Table V. Comparison of adverse events.

\begin{tabular}{|c|c|c|c|c|c|c|c|c|c|c|c|c|}
\hline \multirow[b]{3}{*}{ Adverse events } & \multicolumn{10}{|c|}{ Grades } & \multirow[b]{3}{*}{$Z^{\mathrm{a}}$} & \multirow[b]{3}{*}{ P-value } \\
\hline & \multicolumn{5}{|c|}{ Individualized $(\mathrm{n}=84)$} & \multicolumn{5}{|c|}{ Standard $(n=43)$} & & \\
\hline & 0 & I & II & III & IV & 0 & I & IIa & III & IV & & \\
\hline Nauseaand vomiting & 9 & 19 & 28 & 17 & 11 & 1 & 4 & 10 & 18 & 10 & 3.350 & 0.001 \\
\hline Diarrhea & 69 & 9 & 5 & 0 & 1 & 36 & 4 & 3 & 0 & 0 & 0.217 & 0.829 \\
\hline Hair loss & 0 & 10 & 74 & 0 & 0 & 0 & 6 & 37 & 0 & 0 & 0.324 & 0.746 \\
\hline Aleukocytosis & 5 & 23 & 40 & 12 & 4 & 4 & 11 & 21 & 6 & 1 & 0.438 & 0.662 \\
\hline Thrombocytopenia & 65 & 12 & 6 & 1 & 0 & 31 & 7 & 3 & 2 & 0 & 0.712 & 0.476 \\
\hline Anemia & 7 & 40 & 22 & 11 & 4 & 2 & 9 & 18 & 12 & 2 & 2.921 & 0.004 \\
\hline Hepatic toxicity & 66 & 15 & 3 & 0 & 0 & 35 & 6 & 2 & 0 & 0 & 0.323 & 0.747 \\
\hline Renal toxicity & 83 & 1 & 0 & 0 & 0 & 42 & 1 & 0 & 0 & 0 & 0.473 & 0.637 \\
\hline Neurotoxicity & 13 & 26 & 45 & 0 & 0 & 7 & 15 & 21 & 0 & 0 & 0.441 & 0.659 \\
\hline
\end{tabular}

${ }^{\mathrm{a} M a n n-W h i t n e y ~ U ~ t e s t . ~}$

Table VI. Comparison of PFS and OS.

A, Treatment groups

\begin{tabular}{|c|c|c|c|c|c|}
\hline \multirow[b]{2}{*}{ Survival } & \multicolumn{2}{|c|}{ Standard $(n=43)$} & \multicolumn{2}{|c|}{ Individualized $(n=84)$} & \multirow[b]{2}{*}{ P-value } \\
\hline & Duration, month & $95 \% \mathrm{CI}$ & Duration, month & $95 \% \mathrm{CI}$ & \\
\hline Medium PFS & 4.4 & $3.758-5.042$ & 6.6 & $5.777-7.423$ & 0.018 \\
\hline Medium OS & 11.4 & $10.115-12.685$ & 14.2 & $13.228-15.172$ & 0.008 \\
\hline
\end{tabular}

$\mathrm{B}$, Genotype-specific groups

\begin{tabular}{|c|c|c|c|c|c|}
\hline \multirow[b]{2}{*}{ Survival } & \multicolumn{2}{|c|}{$\mathrm{A} / \mathrm{C} \& \mathrm{~A} / \mathrm{A}(\mathrm{n}=50)$} & \multicolumn{2}{|c|}{$\mathrm{C} / \mathrm{C}(\mathrm{n}=34)$} & \\
\hline & Duration, month & $95 \% \mathrm{CI}$ & Duration, month & $95 \%$ CI & \\
\hline Medium PFS & 6.5 & $5.411-7.589$ & 6.6 & $5.343-7.857$ & 0.139 \\
\hline Medium OS & 14.2 & $13.231-15.169$ & 13.5 & $11.643-15.357$ & 0.512 \\
\hline
\end{tabular}

PFS, progression-free survival; OS, overall survival; CI, confidence interval.

treated by cisplatin together with fluorouracil, patients with the $\mathrm{A} / \mathrm{A}$ or $\mathrm{A} / \mathrm{C}$ genotypes exhibited improved response rate and PFS compared with patients with the $\mathrm{C} / \mathrm{C}$ genotype $(\mathrm{P}<0.01$ and $\mathrm{P}<0.0001$, respectively). Therefore, the present study was designed, according to previous results, to examine the role of the ERCC1 genotype in the individualized treatment of advanced esophageal cancer.

The majority of previous studies investigating ERCC1 utilized immunohistochemical analysis, which has certain disadvantages. Firstly, the tumor tissue for biopsy is small and the amount of tumor cells available may not be sufficient for accurate diagnoses following immunohistochemical staining. Secondly, the analysis in immunohistochemistry is only partially quantitative, and the result is susceptible to investigator bias. The present study was based on the expression of ERCC1 at the molecular level, and therefore was more reliable and accurate. In addition, the analysis of ERCC1 in previous studies primarily arises from the analysis of tissue samples, which is complex $(34,35)$. Schena et al (36) identified that the expression levels of ERCC1 in tumor tissues and peripheral blood were associatedin patients with non-small cell lung cancer and patients with head and neck squamous cell carcinoma.

In the present study, peripheral blood samples were obtained for ERCC1 C8092A analysis. The patients were randomized into the individualized and standard treatment groups at a ratio of 2:1, respectively, based on the genotype. The standard regimen was paclitaxel and cisplatin. In the individualized group, patients with the non-C/C genotype were treated with paclitaxel and cisplatin, and patients with 
A

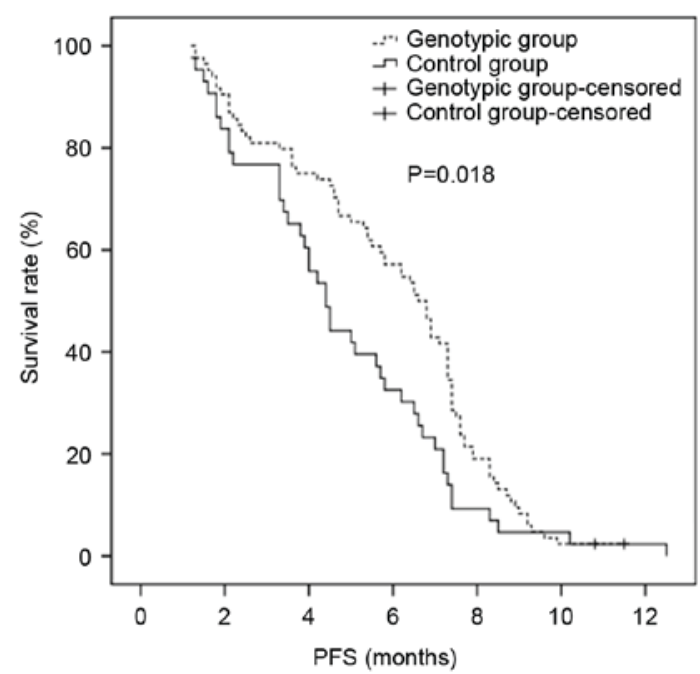

B

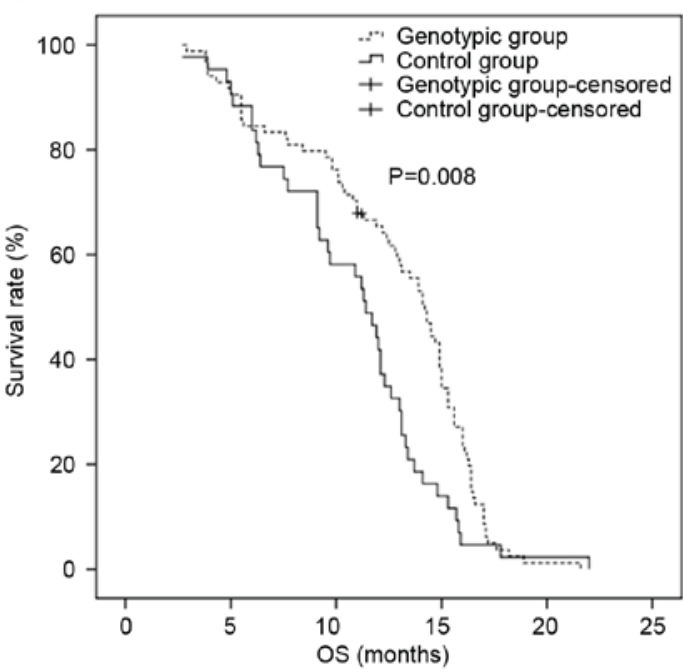

Figure 2. PFS and OS curves in standard and individualized treatment groups. (A) PFS curve. (B) OS curve. PFS, progression-free survival; OS, overall survival.
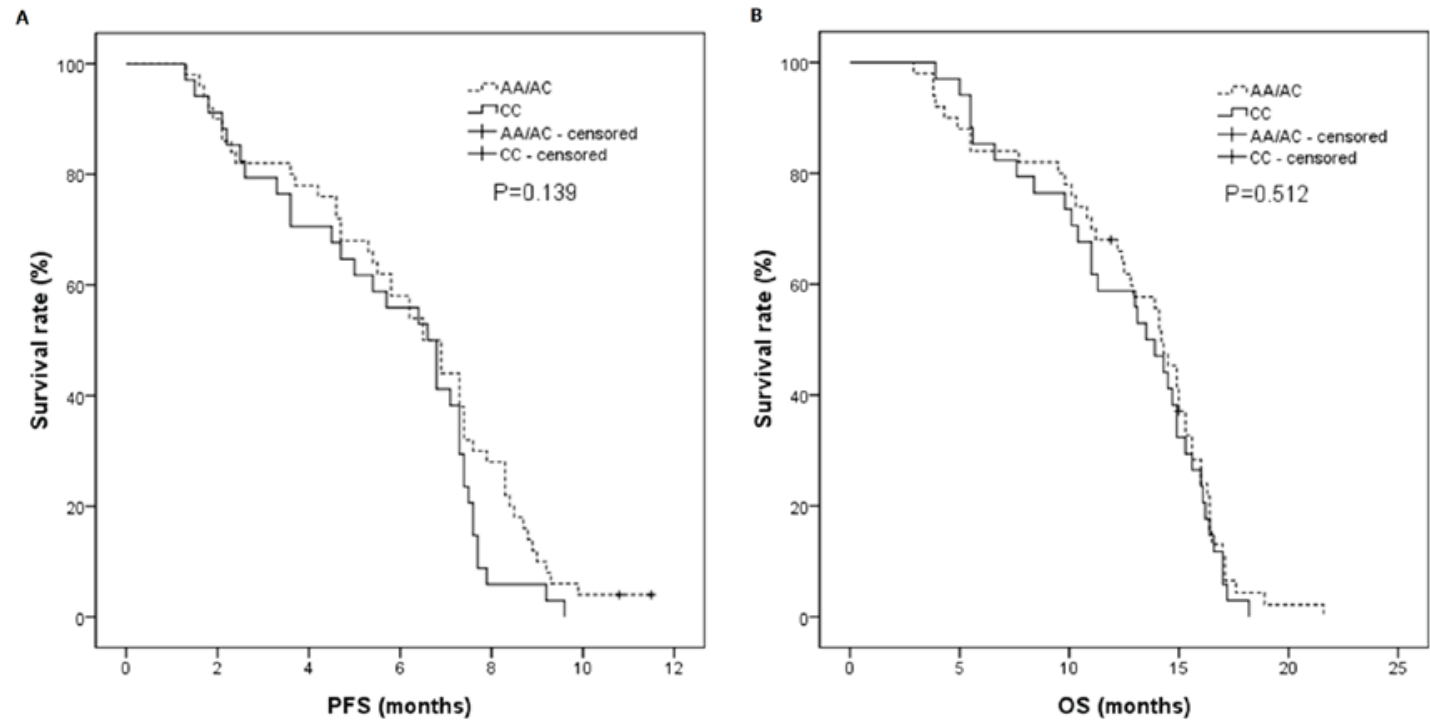

Figure 3. PFS and OS curves in patients with $\mathrm{C} / \mathrm{C}$ and non-C/C genotypes. (A) PFS curve. (B) OS curve. PFS, progression-free survival; OS, overall survival.

the $\mathrm{C} / \mathrm{C}$ genotype were treated with paclitaxel and fluorouracil. Paclitaxel is an anticancer drug with high efficacy. Paclitaxel stabilizes the microtubule polymers and protects them from disassembly, by inhibiting cell mitosis (37). Clinical data has demonstrated that the single-drug efficacy of paclitaxel intreating advanced esophageal cancer is $32 \%$, suggesting that paclitaxel is relatively efficient in advanced esophageal cancer treatment (38). The combination of paclitaxel and cisplatin is one of the most widely-used chemotherapy strategies in paclitaxel therapies. Zhang et al (39) identified that the efficacy of paclitaxel and cisplatin treatment in late-stage esophageal cancer treatment was $48.6 \%$ in a Phase II clinical trial. For patients who are resistant to cisplatin, an alternative choice is paclitaxel combined with fluorouracil. Yun et al (40) revealed that in recurrent or metastatic esophageal squamous cell carcinoma, the efficacies of paclitaxel and capecitabine were $75 \%$ in the first-line and $45 \%$ in the second-line treatment. Matsumoto et al (41) and Schnirer et al (42) also demonstrated positive outcomes, including the RR in the treatment of advanced esophageal cancer with paclitaxel and fluorouracil. Therefore, the present study selected the combination of paclitaxel and fluorouracil as the treatment for patients with the $\mathrm{C} / \mathrm{C}$ genotype that were not sensitive to platinum treatment. The RRs of the individualized and standard treatment groups were 53.6 and $34.8 \%$, respectively. The difference was statistically significant $\left(\chi^{2}=3.095 ; \mathrm{P}=0.046\right)$. The result supported the study hypothesis that individualized treatment based on ERCC1 genotype increases the RR of chemotherapy compared with conventional treatment. The adverse events in the individualized treatment group, including nausea and vomiting, and anemia, were significantly decreased compared with the standard treatment group $(\mathrm{P}=0.001$ and $\mathrm{P}=0.004$, respectively). This indicated that individualized treatment based on 
the genotype of patients avoided the side effects induced by cisplatin on those patients that were not sensitive to cisplatin, increasing the tolerance of chemotherapy in the patients receiving individualized treatment.

The PFS in the standard treatment group was 4.4 months (95\% CI, 3.8-5.0 months) and 6.6 months (95\% CI, 5.8-7.4 months) in the individualized treatment group, which were significantly different $(\mathrm{P}=0.018)$. This result also suggested that the differentiation of treatments for esophageal cancer based on the ERCC1 C8092A genotype may benefit the patients during chemotherapy and prolong the PFS of patients, particularly for those that were not sensitive to platinum treatment. The OS in the standard treatment group was 11.4 months (95\% CI, 10.1-12.7 months) and 14.2 months (95\% CI, 13.2-15.2 months) in the individualized treatment group, which were significantly different $(\mathrm{P}=0.008)$. This may be due to the fact that patients in the individualized treatment group exhibited improved PFS and physical conditions subsequent to PD and a tolerance for chemotherapy compared with the standard treatment group. It may also be due to a failure to control the disease with the second-line treatment following PD in the standard treatment group. In addition, the differences between the supportive treatments may also have an effect on the survival of patients. In the individualized treatment group, the PFS in the $\mathrm{A} / \mathrm{C}$ or A/A group was 6.5 months (95\% CI, 5.4-7.6 months) and 6.6 months (95\% CI, 5.3-7.9 months) in the C/C group, which were not significantly different $(\mathrm{P}=0.139)$. The $\mathrm{OS}$ in the $\mathrm{A} / \mathrm{C}$ or A/A group was 14.2 months (95\% CI, 13.2-15.2 months) and 13.5 months (95\% CI, 11.6-15.4 months) in the C/C group, which were not significantly different $(\mathrm{P}=0.512)$. The analysis within the individualized treatment group indicated that patients with the $\mathrm{C} / \mathrm{C}$ genotype that were not sensitive to platinum treatment exhibited improved PFS and OS compared with AC/AA genotypes when treated based on individual ERCC1 C8092A genotypes.

The present study only focused on the individualized treatment for advanced esophageal cancer based on the ERCC1 C8092A genotype. The population was relatively small, therefore an increase in the study population and decrease in the distinctions between the second-line treatments following $\mathrm{PD}$ is required to additionally support the benefit of the individualized treatment. The present study may provide a molecular basis for the individualized systemic treatment of advanced esophageal carcinoma. It may also be valuable to investigate individualized treatment based on multiple genes simultaneously.

\section{Acknowledgements}

The authors would like to thank Dr Xuan-Liang Zhou (Sangon Biotech Co., Ltd. Shanghai, China) for his technical assistance with the genotype analysis.

\section{Funding}

The present study was supported by the Medical Scientific Research Foundation of Anhui Province (grant nos. 2010B001 and 13zc012) and by the Science Foundation of Anhui Province (grant no. 1408085MH179).

\section{Availability of data and materials}

All data that were generated or analyzed in the present study are included in this manuscript.

\section{Authors' contributions}

$\mathrm{BH}$ and CSJ proposed the study. YWY performed the majority of the experiments and was a major contributor in writing the manuscript. YWY analyzed the data and designed the figures. $\mathrm{XHH}$ and $\mathrm{YFH}$ contributed to the conception of this study, were involved in drafting and revising the manuscript and agreed to be accountable for all aspects of the work. All authors read and approved the final manuscript for publication.

\section{Ethics approval and consent to participate}

The present study was approved by the Clinical Research Ethics Committee of the Anhui Provincial Hospital, which was conducted in accordance with The Declaration of Helsinki. Participants were fully informed of the procedures, and written informed consent was obtained from all patients.

\section{Consent for publication}

Consent for publication was obtained from all patients.

\section{Competing interests}

The authors declare that they have no competing interests.

\section{References}

1. Hao J and Shao K: The epidemiology, current status of management, challenge and future strategy for esophageal cancer in China. China Oncol 21: 501-504, 2011.

2. Domper Arnal MJ, Ferrández Arenas Á and Lanas Arbeloa Á: Esophageal cancer: Risk factors, screening and endoscopic treatment in Western and Eastern countries. World J Gastroenterol 21: 7933-7943, 2015.

3. Okada E, Ukawa S, Nakamura K, Hirata M, Nagai A, Matsuda K, Ninomiya T, Kiyohara Y, Muto K, Kamatani Y, et al: Demographic and lifestyle factors and survival among patients with esophageal and gastric cancer: The Biobank Japan Project. J Epidemiol 27 (SuppI): S29-S35, 2017.

4. Xiang K and Fan Q: Progress in medication treatment of esophageal cancer. World J Gastroenterol 20: 3482-3487, 2012.

5. National Comprehensive Cancer Network (NCCN). NCCN, Fort Washington, PA. https://www.nccn.org/professionals/physician_gls/pdf/esophageal.pdf. Accessed December 14, 2009..

6. Nakamura T, Takahashi M, Niigata R, Yamashita K, Kume M, Hirai $M$ and Yasui H: Changes in blood concentrations of trace metals in cancer patients receiving cisplatin-based chemotherapy. Biomed Rep 5: 737-744, 2016.

7. Sun H, Qin TJ, Ruan ZP, Wang H and Ma Y: Clinical study of vinorelbine combined with cisplatin in the treatment of advanced esophageal cancer. Cancer Res Prevent Treatment 33: 682-685, 2006 (In Chinese).

8. Chen J, He Y, Hu B, Ji CS, Hu CL and Fan PS: Prognostic value of the ERCC1 and TS genetic polymorphisms in advanced esophageal cancer treated with Cisplatin/fluorouracil chemotherapy. Tumor 4: 314-321, 2010.

9. Ryu H, Song IC, Choi YS, Yun HJ, Jo DY, Kim JM, Ko YB and Lee HJ: ERCC1 expression status predicts the response and survival of patients with metastatic or recurrent cervical cancer treated via platinum-based chemotherapy. Medicine (Baltimore) 96: e9402, 2017.

10. Palomba G, Atzori F, Budroni M, Ombra M, Cossu A, Sini M, Pusceddu V, Massidda B, Frau B and Notari F: ERCC1 polymorphisms as prognostic markers in T4 breast cancer patients treated with platinum-based chemotherapy. J Transl Med 12: 272, 2014. 
11. Ting S, Mairinger FD, Hager T, Welter S, Eberhardt WE, Wohlschlaeger J, Schmid KW and Christoph DC: ERCC1, MLH1, MSH2, MSH6, and $\beta$ III-tubulin: Resistance proteins associated with response and outcome to platinum-based chemotherapy in malignant pleural mesothelioma. Clin Lung Cancer 14: 558-567. e3, 2013.

12. Chen C, Wang F, Wang Z, Li C, Luo H, Liang Y, An X, Shao $\mathrm{J}$ and $\mathrm{Li}$ Y: Polymorphisms in ERCC1 C8092A predict progression-free survival in metastatic/recurrent nasopharyngeal carcinoma treated with cisplatin-based chemotherapy. Cancer Chemother Pharmacol 72: 315-322, 2013.

13. Moxley KM,Benbrook DM, Queimado L, Zuna RE, Thompson D, McCumber M, Premkumar P, Thavathiru E, Hines L and Moore KN: The role of single nucleotide polymorphisms of the ERCC1 and MMS19 genes in predicting platinum-sensitivity, progression-free and overall survival in advanced epithelial ovarian cancer. Gynecol Oncol 130: 377-382, 2013.

14. Kalikaki A, Kanaki M, Vassalou H, Souglakos J, Voutsina A, Georgoulias V and Mavroudis D: DNA repair gene polymorphisms predict favorable clinical outcome in advanced non-small-cell lung cancer. Clin Lung Cancer 10: 118-123, 2009.

15. Bradbury PA, Marshall AL, Kulke AH, et al: Prognostic significance of nuclear excision (NER) and base excision (BER) DNA repair gene polymorphisms in esophageal cancer. J Clin Oncol (ASCO Annual Meeting) 25: 2511, 2007.

16. Shan B, He Y, Chen J, Li XQ, Ji CS, Hu CL and Hu B: Clinical outcome of advanced esophageal cancer treated with cisplatin influenced by ERCC1 gene polymorphism in peripheral blood. Chin J Cancer Prevention Treatment 18: 1447-1450, 2010.

17. Edge SB, Byrd DR, Compton CC, Fritz AG, Greene FL and Trotti A (eds): AJCC cancer staging manual. 7th edition. Springer-Verlag, New York, NY, pp103-15, 2009.

18. Rice TW, Blackstone EH and Rusch VW: 7th edition of the AJCC cancer staging manual: Esophagus and esophagogastric junction. Ann Surg Oncol 17: 1721-1724, 2010.

19. Eisenhauer EA, Therasse P, Bogaerts J, Schwartz LH, Sargent D, Ford R, Dancey J, Arbuck S, Gwyther S, Mooney M, et al: New response evaluation criteria in solid tumours: Revised RECIST guideline (version 1.1). Eur J Cancer 45: 228-247, 2009.

20. National Cancer Institute (NCI): Common Terminology Criteria for Adverse Events (CTCAE). Version 4.03. https://evs.nci.nih gov/ftp1/CTCAE/CTCAE_4.03/CTCAE_4.03_2010-06-14_ QuickReference 5x7.pdf. Accessed June 14, 2010.

21. Livak KJ and Schmittgen TD: Analysis of relative gene expression data using real-time quantitative PCR and the 2(-Delta Delta C(T)) method. Methods 25: 402-408, 2001.

22. Polee MB, Hop WC, Kok TC, Eskens FA, van der Burg ME, Splinter TA, Siersema PD, Tilanus HW, Stoter G and van der Gaast A: Prognostic factors for survival in patients with advanced oesophageal cancer treated with cisplatin-based combination chemotherapy. Br J Cancer 89: 2045-2050, 2003.

23. Dasari S and Tchounwou PB: Cisplatin in cancer therapy: Molecular mechanisms of action. Eur J Pharmacol 740: 364-378, 2014.

24. Seiwert TY, Wang X, Heitmann J, Villegas-Bergazzi V, Sprott K, Finn S, O'Regan E, Farrow AD, Weichselbaum RR, Lingen MW, et al: DNA repair biomarkers XPF and phospho-MAPKAP kinase 2 correlate with clinical outcome in advanced head and neck cancer. PLoS One 9: e102112, 2014.

25. Benhamou $S$ and Sarasin A: Variability in nucleotide excision repair and cancer risk: A review. Mutat Res 462: 149-158, 2000.

26. Benhamou S and Sarasin A: ERCC2/XPD gene polymorphisms and cancer risk. Mutagenesis 17: 463-469, 2002

27. Gregg SQ, Robinson AR and Niedernhofer LJ: Physiological consequences of defects in ERCC1-XPF DNA repair endonuclease. DNA Repair (Amst) 10: 781-791, 2011.
28. Tantraworasin A, Saeteng S,Lertprasertsuke N,ArayawudhikulN, Kasemsarn C and Patumanond J: The prognostic value of ERCC1 and RRM1 gene expression in completely resected non-small cell lung cancer: Tumor recurrence and overall survival. Cancer Manag Res 5: 327-336, 2013.

29. Reed E, Dabholkar M, Thornton K, Thompson C, Yu JJ and Bostick-Bruton F: Evidence for in the appearance of mRNAs of nucleotide excision repair genes, in human ovarian cancer tissues. Oncol Rep 7: 1123-1128, 2000.

30. Wood RD: DNA repair in eukaryotes. Annu Rev Biochem 65: 135-167, 1996.

31. Vogel U, Dybdahl M, Frentz G and Nexo BA: DNA repair capacity: Inconsistency between effect of over-expression of five NER genes and the correlation to mRNA levels in primary lymphocytes. Mutat Res 461: 197-210, 2000.

32. Wang J, Zhou XQ, Li JY, Cheng JF, Zeng XN, Li X and Liu P: Prognostic significance of ERCC1 expression in postoperative patients with gastric cancer. Chin J Cancer Res 26: 323-330, 2014.

33. Wang Y, Chen J, Li X, He Y, Hu B, Ji C and Xu J: Genetic polymorphisms of ERCC1 and their effects on the efficacy of cisplatin-based chemotherapy in advanced esophageal carcinoma. Oncol Rep 25: 1047-1052, 2011.

34. Kim M, Ku JH, Kwak C, Kim HH, Lee E, Keam B, Kim TM, Heo DS, Lee SH and Moon KC: Predictive and prognostic value of ribonucleotide reductase regulatory Subunit M1 and excision repair Cross-complementation group 1 in advanced urothelial carcinoma (UC) treated with first-line gemcitabine plus platinum combination chemotherapy. PLoS One 10: e0133371, 2015.

35. Frischknecht L, Meerang M, Soltermann A, Stahel R, Moch H, Seifert B, Weder W and Opitz I: Importance of excision repair cross-complementation group 1 and ribonucleotide reductase M1 as prognostic biomarkers in malignant pleural mesothelioma treated with platinum-based induction chemotherapy followed by surgery. J Thorac Cardiovasc Surg 149: 1539-1546.e1, 2015.

36. Schena M, Guarrera S, Buffoni L, Salvadori A, Voglino F, Allione A, Pecorari G, Ruffini E, Garzino-Demo P, Bustreo S, et al: DNA repair gene expression level in peripheral blood and tumour tissue from non-small cell lung cancer and head and neck squamous cell cancer patients. DNA Repair (Amst) 11: 374-380, 2012.

37. Hossain M, Banik NL and Ray SK: Synergistic anti-cancer mechanisms of curcumin and paclitaxel for growth inhibition of human brain tumor stem cells and LN18 and U138MG cells. Neurochem Int 61: 1102-1113, 2012.

38. Chao YK, Wu YC, Liu YH, Tseng CK, Chang HK, Hsieh MJ, Chu Y and Liu HP: Distant nodal metastases from intrathoracic esophageal squamous cell carcinoma: Characteristics of long-term survivors after chemoradiotherapy. J Surg Oncol 102: 158-162, 2010.

39. Zhang X, Shen L, Li J, Li Y, Li J and Jin M: A phase II trial of paclitaxel and cisplatin in patients with advanced squamous-cell carcinoma of the esophagus. Am J Clin Oncol 31: 29-33, 2008.

40. Yun T, Han JY, Lee JS, Choi HL, Kim HY, Nam BH and Kim HT: Phase II study of weekly paclitaxel and capecitabine in patients with metastatic or recurrent esophageal squamous cell carcinoma. BMC Cancer 11: 385, 2011.

41. Matsumoto H, Kubota H, Higashida M, Yoden E, Hiratsuka J, Haruma K, Nakamura M and Hirai T: Docetaxel/ TS-1 with radiation for unresectable squamous cell carcinoma of the esophagus-a phase II trial. Anticancer Res 34: 3759-3763, 2014.

42. Schnirer II, Komaki R, Yao JC, Swisher S, Putnam J, Pisters PW, Roth JA and Ajani JA: Pilot study of concurrent 5-fluorouracil/paclitaxel plus radiotherapy in patients with carcinoma of the esophagus and gastroesophageal junction. Am J Clin Oncol 24: 91-95, 2001. 